\title{
Contributor's Page
}

\author{
Volume 2, Fall 2014
}

http://dx.doi.org/10.3998/mjs.12333712.0002.0011

M'Lis Bartlett is a PhD candidate in Landscape Architecture and Environmental Justice at the School of Natural Resources and Environment. Her current work employs community based participatory research principles to examine how engaging urban teens in the participatory landscape design process can build collective efficacy for landscape stewardship. She is a recipient of the Rackham Graduate School Graduate Teaching Award. She received her Master of Landscape Architecture form the University of Michigan and a Bachelor of Arts in Fine Art from Oberlin College.

Hillary Bedeian is an Education Assistant at the University of Michigan's Graham Sustainability Institute. She received a Bachelor of Arts from the University of Michigan.

Jacob Bell is a Project Manager at Adaptation International. He engages in projects regarding community based climate change assessment and adaptation planning. He specializes in work with Alaska Native/American Indian communities. He holds a M.Sc. from Trinity College, University of Dublin and a B.A. from Pomona College.

Susan J. Cheng is a $\mathrm{PhD}$ candidate in Ecology and Evolutionary Biology at the University of Michigan. Her current research investigates how cloud conditions impact climate by interacting with changing forest canopy structure to control rates of photosynthesis and forest carbon dioxide uptake. She has recently earned a two-year fellowship from the University of Michigan Graham Environmental Sustainability Institute and a research award from the Michigan Space Grant Consortium. She received a MS in ecology and evolutionary biology from the University of Michigan and a BA in environmental science from Columbia University.

Kathryn Conlon is a postdoctoral research fellow with the National Center for Atmospheric Research and the Centers for Disease Control and Prevention. Her current research evaluates how changes in both climate and urban form influence intra-urban temperature distributions, and, ultimately, populations exposed to ex- 
treme temperatures. She received a $\mathrm{PhD}$ in Environmental Health Sciences from the University of Michigan School of Public Health and a Masters in Public Health from the Rollins School of Public Health at Emory University.

Garry Green is a lecturer II in the Earth and Resource Science Department at the University of Michigan-Flint. Primary responsibilities include teaching environmental science laboratories as well as landscape photography and world regional geography. He has received a master's of arts in education in technology and a bachelor's of science from the University of Michigan-Flint.

Hansi Hals is the Environmental Planning Manager for the Jamestown S'Klallam Tribe on the Olympic Peninsula of Washington State. Her work focuses on the protection and restoration of tribal treaty resources, especially salmon and shellfish. She currently sits on the Washington State Department of Health Puget Sound Septic Financing Advisory Committee. She received a Master of Science in Natural Resources Administration and Management from the University of New Hampshire and a Bachelor of Arts from Colby College.

Patrick Harlin is a DMA candidate in Music Composition at the University of Michigan. His dissertation investigates sound and sustainability and the preservation of sonic landscapes focusing on remote regions of the Amazon rainforest and Book Cliffs, Utah. Patrick's compositions have been performed by the St. Louis Symphony Orchestra, University of Michigan Symphony Band, and this upcoming year by the Atlantic Classical Orchestra and Calgary Philharmonic among others. He received a Masters in composition from the University of Michigan and Bachelors from Western Washington University.

Lingli He has a $\mathrm{PhD}$ from the Civil Engineering program at the University of Michigan. Her current research evaluates the impact of climate change on forest species in Northern Michigan. She recently served as co-chair for professional development at the Graduate Society of Women Engineers at the University of Michigan. She received a master of science from the University of Michigan, and a bachelor of science from Huazhong University of Science and Technology.

Joel Howrani Heeres is the Principal Supervisor of the Performance Center at DTE Gas Company. His current work involves developing and tracking performance metrics for Gas Operations. He previously developed Climate Action and 
Sustainability Plans for 10 cities in Southeast Michigan while serving as the Sustainable Communities Coordinator at EcoWorks. He received a Dual Masters of Urban Planning and the Environment and a Bachelor of Arts from the University of Michigan, Ann Arbor.

Kimberly Hill Knott is the Director of Policy at Detroiters Working for Environmental Justice (DWEJ), primarily handling state and federal policy initiatives around air quality and workforce development, including green jobs. She also serves as the Project Director of the Detroit Climate Action Collaborative, which is leading the development of the city of Detroit's Climate Action Plan. As a result of this work, she was nominated and selected for the White House Champions of Change Award for Community Resilient Leaders. Additionally, last year, she was one of 100 women invited to participate in the White House Women's Summit on Climate and Energy. Kimberly received a Bachelor of Science from the University of Wisconsin-Milwaukee and a Master's of Education in Educational Administration from Temple University in Philadelphia.

Richard Hill-Rowley is an Associate Professor in the Department of Earth and Resource Science at the University of Michigan-Flint. He has been involved in ground water, land use and planning issues in Flint and Genesee County, Michigan for the last 25 years. He initiated the Urban Alternatives House project and served as project director while the renovation was completed. He received a Master in Geography from the University of Georgia and a PhD in Geography from Michigan State University.

Geoffrey Jacquez is President of BioMedware and Professor of Geography at the State University of New York at Buffalo. He also is Adjunct Associate Professor of Environmental Health at the University of Michigan, and is co-science Director of the CRCSI Australia Health Program. His current research focuses on the modeling, control and surveillance of disease, with a particular emphasis on cancer. $\mathrm{He}$ has a BS and Masters from the University of Michigan, and a PhD in evolutionary biology from SUNY Stony Brook.

Thomas Jenkinson is a Ph.D. candidate in the Department of Ecology and Evolutionary Biology at the University of Michigan. His dissertation research is focused on using genetics to track the movement of newly discovered wildlife diseases. Thomas is currently conducting fieldwork on conservation and biodiversity projects 
in southeastern Brazil, and the results of his research team's most recent study are featured in the journal "Proceedings of the National Academy of Sciences." $\mathrm{He}$ received an M.S. in Ecology and Systematic Biology from San Francisco State University, and a B.S. in Biology from Oregon State University.

Rebecca Mandell is a PhD candidate at the University of Michigan School of Public Health. Her research focuses on the intersection between the environmental justice and reproductive justice movements, with implications for policy and advocacy initiatives that address inequities in exposure to environmental toxicants and associated population-based inequities in reproductive health. She was recently a fellow in the Reach the Decision Makers program, a training fellowship run by the UCSF Program on Reproductive Health and the Environment. She holds a Bachelor of Arts from Harvard University and a Master of Science from the Harvard School of Public Health.

Leila Mekias is a Climate Fellow at Detroiters Working for Environmental Justice, where her work has focused primarily on climate change education. Leila received a Master of Science from the University of Michigan and a Bachelor of Arts from Southern Methodist University.

Dr. Ian Miller is Washington Sea Grant's coastal hazards specialist, working out of Peninsula College in Port Angeles as well as University of Washington's Olympic Natural Resources Center in Forks. A skilled science communicator and media spokesperson, Dr. Miller works with coastal communities on the Olympic Peninsula to increase their ability to plan for and manage coastal hazards, including tsunami, chronic erosion, coastal flooding and hazards associated with climate change. To accomplish this, he uses a suite of tools including outreach, applied research, synthesis of existing science, and coordination to help coastal communities access funding and expertise to achieve their goals and implement their plans.

Sarah Mills is a PhD candidate in the Urban and Regional Planning program at the University of Michigan and a Policy Analyst at the Center for Local, State, and Urban Policy (CLOSUP) at the Gerald R. Ford School of Public Policy. Her current research focuses on the impact that wind energy projects have on owners of farmland and farming communities more generally. She recently co-authored a report on the opinions of Michigan local government leaders on wind energy, as well as a report on public opinion of wind energy throughout the Great Lakes region. She 
has a Master of Philosophy in Engineering for Sustainable Development from the University of Cambridge (UK), and a Bachelor of Science in Mechanical Engineering from Villanova University.

Michelle Reicher Newstadt is a PhD candidate in Science Education at the University of Michigan. Her current research explores middle school students' climate change knowledge and stances. She was a Dow Doctoral Fellow at the University of Michigan and recently named as a finalist for the NAEd/Spencer Dissertation Fellowship. She received a Master's degree in Environmental Conservation Education from New York University, and a Bachelor of Arts in Geological Science from Brown University.

Marie O'Neill is Associate Professor of Epidemiology and Environmental Health Sciences at the University of Michigan School of Public Health. Her research interests include health effects of air pollution and temperature extremes, climate change and health; international health; and environmental equity. She served as an advisor to the 2014 U.S. National Climate Assessment. She has a B.A. from Brown University, an M.S. from Harvard University and a PhD in Epidemiology from the University of North Carolina at Chapel Hill.

Jamie Parks is a community transportation expert, with experience in multimodal transportation planning, pedestrian and bicycle safety, project prioritization, and performance measurement. Jamie has worked with dozens of clients throughout the country to develop transportation projects and policies that reduce greenhouse gas emissions, increase equity, and make cost-effective use of limited resources. Jamie has a Bachelor's degree in History and Mathematics from Johns Hopkins University, and a Master's degree in Transportation Engineering from Northwestern University.

Sascha Petersen is a founder of Adaptation International, an organization focused on helping communities build climate resilience. He works directly with communities to bridge the gap between climate science and action. He was a Lead Author for the Great Plains Region of the 2014 National Climate Assessment and serves on an advisory committee for the Southern Climate Impacts Planning Program and the EPA's Water Resources Adaptation to Climate Change Working Group. He received a Master's Degree from the University of Washington focused on climate change science and policy and a Bachelor of Arts from Pomona College. 
Nicholas B. Rajkovich, PhD, AIA is an Assistant Professor at the University at Buffalo. His research investigates the intersection of energy efficiency, renewable energy, and adaptation to climate change. In 2011, he was awarded a Graduate Research Fellowship from the National Science Foundation and a Doctoral Fellowship from the Graham Environmental Sustainability Institute at the University of Michigan. He received a PhD in the Urban and Regional Planning Program from the University of Michigan, a Master of Architecture from the University of Oregon and a Bachelor of Architecture from Cornell University.

Jennifer Reeve is associate professor of Organic and Sustainable Agriculture in the department of Plants Soils and Climate at Utah State University (USU). Her current research focuses on nutrient management and soil health in organic and integrated tree fruit, vegetable, pasture and grain systems. She is also chair of the Southern Coordinating Committee: Quantifying the linkages among soil health, organic farming and food. In 2012 she received an award of civically engaged scholar from the Utah Campus Compact for her work with the USU Student Organic Farm. Originally from England, she earned a Bachelor of Science in Ecology from the University of Sheffield in 1995 followed by a MS in Soil Science from Washington State University in 2003 and a PhD in Soil Science from Washington State University in 2007.

Danielle Zoé Rivera is currently a doctoral candidate in Urban and Regional Planning at the University of Michigan, with a focus on Community Development and Border Studies. Her current research focuses on issues of participation and collaboration in service delivery programs in informal communities. Prior to arriving at the University of Michigan, she taught in architecture studios at The Pennsylvania State University and worked as an architectural designer. She received a Master of Architecture from the University of Pennsylvania and a Bachelor of Architecture from The Pennsylvania State University.

Robert Rommel is a Senior Software Developer and Researcher at BioMedware, Inc. He has helped to develop several of BioMedware's software tools for analyzing spatial and temporal patterns and has also performed research on dynamical models for systems ranging from climate change to college-level alcoholism. He received a Bachelor of Arts from Princeton University. 
Richard B. Rood is a Professor at the University of Michigan in the Department of Atmospheric, Oceanic, and Space Sciences and the School of Natural Resources and the Environment. He is the expert climate change blogger for Wunderground.com. His current research focuses on the usability of climate knowledge in planning, design, and management. He is a Fellow of the American Meteorological Society and recently served on the National Research Council's Committee on a National Strategy for Advancing Climate Modeling. He received a Ph.D. in Meteorology in 1982 from Florida State University and a B.S. in Physics in 1976 from the University of North Carolina.

Byron Rot worked for the Jamestown S'Klallam Tribe for almost 15-years. He was the project manager and technical lead for the Jamestown S'Klallam Tribe's Climate change planning and risk analysis plan. He also led the Tribe in Salmon habitat protection/restoration and was the co-manager of the $\$ 6$ million Jimmycomelately Creek restoration project. In addition, Byron managed several logjam-salmon projects on the Dungeness River, including a \$1 million ELJ project at RR Bridge Park and a logjam project on McDonald Creek. He also delineated the Dungeness Channel Migration Zone using the Ecology methodology, which is incorporated into the Clallam County SMP.

Byron has a Masters from the University of Washington in Forest Ecosystems and a certificate from the Wilderness Awareness School in Duvall Washington.

Simone Sagovac is Project Director for Southwest Detroit Community Benefits Coalition, working in the Delray community that hosts steel mills, a coal-fired energy plant, the country's largest wastewater plant, and soon the new bridge to Canada with thousands of daily diesel trucks. The coalition is seeking pollution remedies with legally-binding community benefits agreements, and secured initial language in the 2012 U.S.-Canada Crossing Agreement. Simone earned a BA in Urban Planning at Wayne State University.

Natalie Sampson is an Assistant Professor in the Department of Health and $\mathrm{Hu}-$ man Services at the University of Michigan (U of M)-Dearborn. Her research focuses on a variety of social and environmental determinants of health, including environmental justice, public participation, freight transport, climate change, land use, and water infrastructure. Dr. Sampson partners with communities and local government to plan and evaluate program, policy, and land use interventions to 
improve health equity. She received a PhD from the School of Public Health at U of M, a Master of Public Health from the School of Community Health at Portland State University, and a Bachelor of Science from the School of Natural Resources and the Environment at $\mathrm{U}$ of $\mathrm{M}$.

Mike Shriberg, Ph.D., is Education Director at the Graham Environmental Sustainability Institute and Lecturer in the Program in the Environment, Earth \& Environmental Sciences and the Michigan Community Scholars Program at the University of Michigan. In addition to teaching courses such as "Sustainability and the Campus" and "Sustainability Leadership Development," he leads the Graham Undergraduate Sustainability Scholars Program, Dow Sustainability Fellows Program, Planet Blue Ambassadors Program and efforts to integrate sustainability across the curriculum at the University of Michigan. His research and practice focuses on organizational change and sustainability leadership, with an emphasis on higher education institutions, and he is the North American Editor of the International Journal of Sustainability in Higher Education. He earned an M.S. and Ph.D. in Resource Policy and Behavior from the University of Michigan's School of Natural Resources and Environment and a B.S. in Biology and Society from Cornell University.

Dominic Smith is the Project Manager/Health Educator for the Michigan Department of Community Health-Climate \& Health Adaptation Program. She provides technical expertise for local health departments conducting Health Impact Assessments and advises implementation of the Centers for Disease Control \& Prevention, Building Resilience Against Climate Effects framework. Dominic has a Bachelor of Science in Health Education from the University of Tennessee and a Master of Science in Health Services Administration from Central Michigan University.

Lauren B. Stadler is a PhD candidate in Environmental Engineering at the University of Michigan studying sustainable biological wastewater treatment processes. Her research is focused on microbial community characteristics and micropollutant fate in low oxygen wastewater treatment systems. Through a combination of experimental work and systems analyses, she aims to understand inherent tradeoffs in sustainable wastewater treatment and micropollutant fate. Lauren received her M.S. in Environmental Engineering from the University of Michigan and her B.S. in Engineering from Swarthmore College. Lauren also worked in environmental 
consulting designing algae pond systems for wastewater treatment and received a Fulbright Scholarship to do research in New Delhi, India.

Missy Stults is a PhD candidate and researcher in the Urban and Regional Planning Program and the School of Natural Resources and Environment at the University of Michigan. Her research and work focuses on helping cities to build their resilience to climate change and natural disasters. Missy is a founding member of the American Society of Adaptation Professionals, a member of the Great Lakes Adaptation Assessment for Cities team, and a frequent consultant on local climate adaptation initiatives. Missy holds a Masters of Arts in Climate and Society from Columbia University and a Bachelors of Science in both Marine Biology and Environmental Science from the University of New England.

Brian D. Vickers is a Ph.D. candidate in the Cognition and Cognitive Neuroscience program at the University of Michigan. His research investigates the decision processes associated with consumption, including the acquisition and discarding of possessions. He uses a multi-method approach including fMRI, physiology, and behavioral methods. 